\title{
Research on Macro Teaching Ecosystem Based on Value Co-creation: Taking International Economics and Trade as an Example
}

\author{
Shuzhu Jiang*, Aiying Jiang \\ School of Economics, Shandong Technology and Business University, Yantai, China \\ "Corresponding author. Email: nbjsz@163.com
}

\begin{abstract}
Under the background of the popularization of higher education, any major needs to cooperate with employers to build a macro-teaching ecosystem based on value co-creation and expand its own realistic niche. There are eight ways to build a value co-creation-oriented macro-teaching ecosystem, including plan revision, curriculum co-construction, textbook construction, subject competition, internship guidance, order training, expert lectures and teacher training. The motivation mechanism includes introducing a professional construction incentive mechanism, implementing the division of speciality construction tasks, establishing a school-enterprise cooperation and communication mechanism, and carrying out major's digital transformation.
\end{abstract}

Keywords: Value co-creation; Teaching ecosystem; School-enterprise cooperation

\section{INTRODUCTION}

Teaching and educating people is not only the fundamental task of undergraduate colleges and universities, but also a systematic project. In recent years, the application of mobile Internet technology in teaching has enabled the rapid development of online teaching, and the concept of teaching ecosystem has received more and more attention. However, the current domestic research on the teaching ecosystem mainly focuses on the classroom teaching ecosystem. some only discusses the construction of the classroom teaching ecosystem from the perspectives of teachers, students, managers, and information flow[1] [2]; some focus on discussing the teacher-student relationship in the process of relying on Internet teaching[3], the role of teachers in online teaching[4], Internet-based teaching and other teaching such as flipped classrooms model reform [5] [6] [7]. These studies have positive significance for promoting the reform of teaching methods based on the mobile Internet, but they can basically be classified as micro-teaching ecosystem research. There are very few macro-teaching ecosystem researches that include more adaptive agents and the environment. Some literature mentions it, such as "The construction of a macro-teaching ecosystem based on a digital platform"[8], but it was only discussed around the construction and acquisition of digital curriculum resources.
The current higher education has entered the stage of popularization. In 2020, the number of college graduates have reached 8.74 million. The supply and demand of college graduates has changed from short supply to oversupply, and the talent training of colleges and universities must fully consider the market demand. In order to successfully run undergraduate education and cultivate high-quality talents that meet the needs of society, it is necessary to establish a micro-teaching ecosystem and to promote the reform of teaching methods, furthermore, to build a macro-teaching ecosystem. From the perspective of the macro teaching ecosystem, it is an important task to clarify how to make full use of internal and external resources, especially the use of social enterprise resources, and improve the quality of talent training through school-enterprise cooperation. This requires an in-depth study of the macro-teaching ecosystem. Taking the undergraduate major of international economics and trade as an example, this paper discusses the construction and dynamic mechanism of macro teaching ecosystem based on value co-creation under the background of mobile Internet.

\section{BASIC CONCEPTS}

The basic concepts involved in this article include teaching ecosystem, ecological niche, value co-creation and macro teaching ecosystem. 


\subsection{Teaching Ecosystem}

The teaching ecosystem is derived from the ecological concept of biology. Ecosystem is a dynamic balance system composed of a biological community and its environment. The biological community is the biological part of the system, which is composed of certain animals, plants and microorganisms that are interdependent and influence each other within a certain range. The environment is the non-living part of the system. The teaching ecosystem should also include two parts: the biological subject and the environment. The biological subject includes colleges and universities (internally divided into students, majors, departments, management and teaching assistant departments, etc.), enterprises, governments, other colleges and universities, service providers, etc. Colleges and universities in the teaching ecosystem are producers, and all majors cultivate and export all kinds of talents through the teaching activities of professional teachers; enterprises and institutions that recruit talents are consumers. Talent is the product which bridge universities and enterprises.

\subsection{Ecological niche}

Niche is defined as "the position and status of an organism in a community and ecosystem, and this position and status are determined by the organism's morphological adaptation, physiological response, and unique behavior" (Zhou, 2012). Niche can be divided into basic niche and actual niche. The basic niche means all the resources that a population can use without any competition. However, there is competition between populations, which makes any population to use only part of it, that is, the actual niche. A major needs to obtain more resources and expand the real niche through systematic speciality construction, so as to obtain a larger living space.

\subsection{Value co-creation}

In the traditional value creation process, the company independently decides which products and services to provide on the basis of judging customer needs, that is, value is created within the company and then exchanged with customers in the market. Customers or consumers are completely passive and do not participate in the process of value creation. The rapid advancement of information technology makes it possible for consumers to participate in the process of value creation. Internetbased e-commerce has developed rapidly, from early online advertising to later release of product graphic information and online transactions, to the current short video, live streaming, self-media marketing, and online customization. Consumers can not only give feedback on the product experience to the manufacturer, but they can also directly inform the manufacturer of their needs or creativity, so that the manufacturer can improve the product or make customized production. This is a value co-creation process which involves users and consumers. The relationship between enterprises and consumers is no longer a simple buying and selling relationship, but a winwin partnership. Correspondingly, the value creation concept centered on enterprises or products has been transformed into a co-creation value concept centered on experience. Similarly, colleges and universities, a special "production department", are also facing the problem of relying on value co-creation to reverse the dilemma that supply exceeds demand.

\subsection{Macro teaching ecosystem}

The teaching ecosystem can be divided into two categories: micro and macro. The macro teaching ecosystem should include universities, service providers, majors, enterprises, governments, teachers, students, etc. Among universities there are not only a biological community that competes with other universities; but also work as an ecosystem, including majors, teachers, students, etc., as shown in Figure 1. Firstly, there is competition and cooperation among the various majors in a given universities. Each major needs to compete for the limited resources, at the same time, needs mutual support and coordinated development. Secondly there is a competitive relationship with colleges and universities, and they need to compete for the real niche. Thirdly, the relationship between colleges and enterprises and institutions is the relationship between producers and consumers. In the stage of popularization of higher education, enterprises and institutions should participate in the process of talent training and promote the transformation of the macro teaching ecosystem to a value co-creation type.

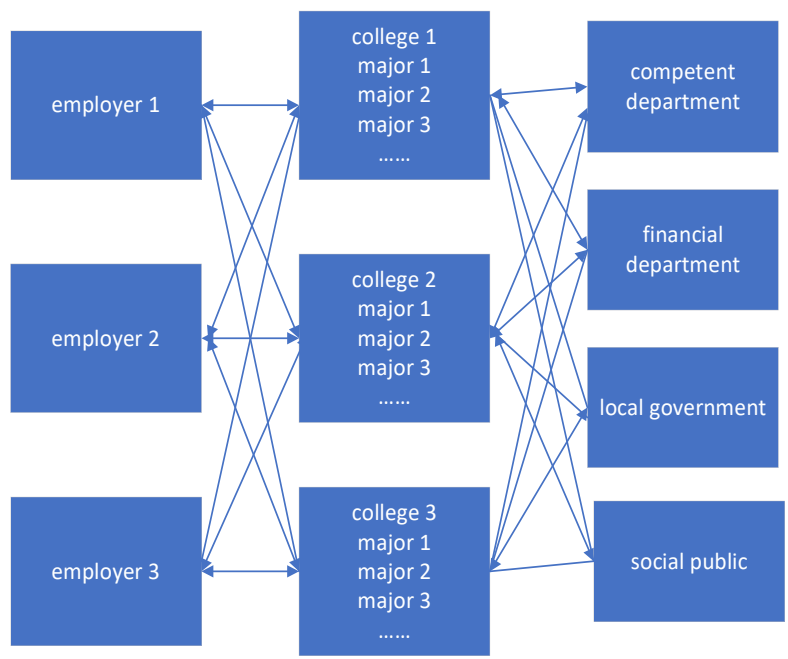

Figure 1 Schematic diagram of the macro teaching ecosystem 


\section{THE PROBLEMS FACED BY THE CONSTRUCTION OF THE MACRO TEACHING ECOSYSTEM}

The construction of the macro-teaching ecosystem is a new proposition, and there is no systematic theoretical research about it. The university level generally emphasizes scientific research, which is bad for the construction of the macro-teaching ecosystem.

\subsection{The concept of a macro teaching ecosystem has not been established yet}

A specific major is similar to a species in a biological community. On the one hand, it has its own ecological niche in the school community, which is different from other majors; on the other hand, a major not only has to compete with other majors in the school to obtain resources for survival and development, but also faces competition from other domestic universities in the same ecological niche with the same major. This competition is embodied in many aspects such as enrollment, employment, further education, resource acquisition, and social reputation.

The macroscopic teaching ecosystem which belongs to social systems is similar to the natural ecosystem, but there are obvious differences. In the natural ecosystem, the biological community will also evolve to adapt to the environment, however, it has no consciousness, unlike humans who can think, learn, and constantly expand their niche. As an ecological community, if a university has the awareness of opening up schools, it will strengthen its ties with the government, enterprises, other universities, and the public. At the same time, it will also choose frontal competition or dislocation competition based on its own and its competitors. Employers participate in the talent training process and cultivate application-oriented highquality through value co-creation, which will help enhance professional market competitiveness.

\subsection{It is urgent to guide teachers to devote themselves to professional construction}

The survival of the fittest is an evolutionary view. For a major to develop well, it must make achievements in speciality construction and talent training, and be able to be recognized by peers, employers, students and parents. But knowing is easy and doing is hard, what exactly can we do to achieve this goal? Not only must there be a teaching team led by a serious and responsible professional leader, but also institutional guarantees at the university level and the support of the leaders at the school and academy levels. The key factor in the competition between majors lies in the teaching staff, in order to give full play of the teaching staff, the school's guarantee and guidance, financial support are important, which for teachers to carry out teaching research, guide subject competitions, etc., and encourage teachers to devote themselves to teaching and talent training, such as carrying out teaching research and guiding subject competition.

\section{THE PATH TO CONSTRUCT A MACRO TEACHING ECOSYSTEM BASED ON VALUE CO-CREATION}

In order to cultivate high-quality talents that meet the needs of employers, colleges and universities must work closely with employers and coordinate education through school-enterprise cooperation, so that employers can fully participate in the process of talent training and achieve value co-creation. In order to ensure the sustainability of this kind of cooperation, universities and enterprises need to sign certain types of cooperation agreements to establish a macro teaching ecosystem based on value co-creation, so that both universities and enterprises can benefit from it and achieve a win-win situation. Through all-round cooperation, the quality of students trained by universities has not only improved, but they are also more suitable for social needs. By participating in talent training, companies not only realize their social value and gain social recognition, but also can contact students in advance, find outstanding talents early, and then make use of talents to bring greater benefits. The specific measures for enterprises to participate in the talent training process and cultivate excellent talents through value co-creation mainly include the following 8 aspects (only taking the major of international economy and trade as an example):

\subsection{Teaching plan revision}

The talent training program determines the four-year knowledge system of undergraduates and is the key to talent training. However, if there is no participation of employers, just relying on experience or learning from other colleges and universities to revise training programs, it is likely to cause the training of talents out of touch with social needs, and affect the employment and long-term development of students. With the continuous acceleration of technological progress, many industries are constantly changing, and the original knowledge structure is not enough to meet the new needs of industry development. On the one hand, foreign trade companies or foreign-funded companies should be invited to participate in the formulation and revision of the talent training plan. On the other hand, teachers conduct research in the company, and to solicit opinions and suggestions from employers on the curriculum system, so that the curriculum system can ensure that students can be competent in the industry. Knowledge and ability to work. If possible, people in the industry can be invited to form an industry-teaching cooperation steering committee. 


\subsection{Co-construction of courses}

Curriculum co-construction is one of the important means to introduce social resources and solve the disconnection between university teachers and practice. There are very few teachers with experience in the foreign trade industry, and there is a shortage of dual-qualified teachers. After graduating, most of them will be engaged in practical work related to import and export, except for a small number of students who have succeeded in the postgraduate entrance examination. Therefore, some innovations can be made in practical courses, especially in cross-border e-commerce courses. College teachers can be responsible for theoretical links, and foreign trade business managers or senior salesmen with rich practical experience can be responsible for experimental training. Relying on the online teaching of mobile Internet, people in the industry can carry out remote teaching and practice guidance to overcome the inconvenience caused by time and space distance.

\subsection{Construction of teaching materials}

It is both necessary and feasible for employers to participate in the construction of teaching materials for practical courses. The necessity is reflected in three aspects: First, the teachers who compiled the textbooks in the past usually lacked sufficient practical experience, and excess theory and insufficient practice led to the dilution of practical application of the textbooks. Second, less understanding of trends may result in teaching materials lagging behind practice. Third, because foreign trade involves different countries in the world, there are differences in politics, economy, law, and culture among countries in the world, and countries' understanding of the same issue may differ. Companies often encounter some special situations in their practical operations, which are completely different from what is mentioned in the textbook. The feasibility is reflected in the fact that foreign trade companies have accumulated a lot of experience and cases in long-term import and export practices. Some cases can be sorted out and introduced to the textbooks, which make the textbook is not only theoretical but also practical. Co-construction will help students learn how to solve practical problems.

\subsection{Subject contest}

Subject contest is very important to the cultivation of students' abilities. It can improve students' professional skills and overall quality, and broaden their horizons. At present, there are many subject contests in the international trade major. The most influential ones are the POCIB National Foreign Trade Practice Ability Competition, the OCALE National Cross-border Ecommerce Innovation and Entrepreneurship Competition, and the National Business Elite Challenge International Trade Competition. In addition, there are also the
National Undergraduate E-commerce "Innovation, Creativity, and Entrepreneurship" Challenge and the Internet + Contest. Both of these competitions have set up a cross-border e-commerce track, and students majoring in international trade can also participate in. In the above competitions, except for POCIB, other competitions can invite companies to send people to participate in the guidance, and companies can also provide funding in terms of funding. Colleges and universities can also organize competitions in related disciplines and invite companies to name or sponsor them, especially competitions such as the Business Elite Challenge International Trade Competition. This is an opportunity for companies to show their strength and reach out to students.

\subsection{Internship guidance}

Internship is an important part of the integration of undergraduate teaching and practice. Undergraduates need to participate in graduation internship at least before graduating. Some majors also have knowledge internships. Since many colleges and universities across the country have undergraduate majors in international economics and trade, the overall enrollment scale of this major is relatively large, and a single company can accept a small number of interns at a time, so the internship is often difficult to arrange in a unified manner, and students usually need to contact the internship unit themselves. Colleges and universities can sign teaching practice base agreements with companies, hire key business personnel of the company to serve as internship instructors, clarify the rights and obligations of both parties, companies provide internship positions, and make two-way choices with students. If the number of internship bases is large enough, the problem of internship can be solved completely. Colleges and universities can also invite enterprises to jointly build internship bases on campus. The school provides venues and equipment, and the enterprise arranges relevant personnel for centralized internship guidance.

\subsection{Order training}

Although there are a lot of college students graduating each year, it is still difficult for companies to recruit fresh graduates that fully suit their needs. For some large companies, or a group of companies with common needs, they can sign a commissioned training agreement with colleges and universities to conduct order-based training. However, this method is difficult to implement at the undergraduate level. It is more difficult to carry out largescale order-based training. It needs to recruit students after enrollment, train them separately from normal courses, or set up special elective modules in the curriculum system. Relevant courses or internships are jointly responsible by enterprises and universities. 


\subsection{Expert lectures}

There is no shortage of experts and scholars in universities, and students often have the opportunity to hear lectures, but these lectures by experts and scholars usually do not involve practical operations. In order for students to have a clearer understanding of the future employment positions, working environment, and development prospects of the major they are studying, the university should make full use of the human resources of the company and regularly invite corporate managers and business personnel to give lectures. For senior students, lectures on practical aspects, employment or career planning can be arranged to help students make reasonable decisions in employment; for students in lower grades, it mainly concerns the current situation and development trend of the industry, and what kind of talents business needs, so that students can clarify the direction of their efforts.

\subsection{Teacher training}

The construction of applied undergraduate majors usually requires a certain proportion of dual-qualified teachers. Arranging teachers to work in an enterprise is another important way to train dual-qualified teachers. In view of the fact that teachers with high academic qualifications often lack practical experience, practical teachers should be encouraged to take temporary posts in foreign trade companies, so that teachers can put the theory into practice and obtain corresponding practical experience, so that they can better teach practical courses and guide students to participate in subjects competition and employment guidance. Relevant cooperating units should provide temporary positions to assist in solving the accommodation problems of temporary teachers. Colleges and universities should issue corresponding policies to reduce or exempt the teaching workload of temporary teachers, and even give appropriate preference in terms of job title evaluation and job appointment.

\section{THE DYNAMIC MECHANISM OF THE MACRO TEACHING ECOSYSTEM BASED ON VALUE CO-CREATION}

The previous discussion has discussed the path to realize the value co-creation-oriented macro-teaching ecosystem. It is also necessary to establish a corresponding dynamic mechanism, so that a major can have the willingness and ability to cooperate with enterprises for a long time, and carry out speciality construction and talent training together. The dynamic mechanism should include the following four aspects:

\subsection{Introducing an incentive mechanism for speciality construction}

Schools and colleges should introduce corresponding system measures to affirm the efforts and achievements of professional leaders and professional teachers in speciality construction. In particular, the Ministry of Education has highlighted the importance of talent training in the construction of first-class majors and the fifth round of subject evaluation. Undergraduate colleges and universities should issue corresponding policies to encourage speciality construction in accordance with the guidance of the Ministry of Education, provide necessary institutional guarantees and financial support for speciality construction, recognize the speciality construction workload, give appropriate rewards for the achievement of landmark results, and recognize them in the job evaluation.

\subsection{Divisding speciality construction tasks}

After obtaining the institutional guarantee, the professional person in charge should organize an argumentation, clarify the stage goal of the speciality construction, and then make full use of the professional teachers and even other teachers in the school, break down the speciality construction tasks, and strive for all staff to participate in the speciality construction. In contrast to each indicator, one teacher is assigned to be responsible for the promotion of the project, and an assessment will be conducted at the end of the year. Among the above-mentioned 8 measures, some of them require professional responsible persons to communicate with the enterprise, and some of them can be undertaken by teachers. For example, arranging external intern instructors, expert lectures, can be presented by the professional leader; while the construction of teaching materials and subject contests require the participation of enterprises, the project leader can directly coordinate.

\subsection{Establishing a school-enterprise cooperation and communication mechanism}

It is necessary to establish some form of schoolenterprise cooperation mechanism to strengthen the connection and communication between schools and enterprises, and do not rely solely on the relationship between individuals and enterprises. The more common cooperation mechanism is to establish a teaching practice base by signing a contract with a company, and to list it in the company, and then send teachers to take students to the company for internship every year, invite companies to the school to participate in double election meetings, and invite corporate executives to come to the school for lectures or exchanges. If there are a large number of practice bases, a WeChat group or QQ group can be established that includes multiple teachers and enterpriserelated personnel for each base to facilitate frequent 
communication and contact; if a WeChat group that includes all the practice base contacts and all teachers has been established, there is no need to worry about interruption of contact due to personnel changes.

\subsection{Promoting digital transformation of speciality construction}

Digital transformation of speciality construction is a new trend, including multiple meanings. First, use cloud technology and big data technology to build a microteaching ecosystem to realize the digitization of teaching materials, the digitization of teaching processes, and the digitization of teaching supervision. Second, speciality construction is a systematic project with complex content and scattered results. For example, there may be dozens of records per year only for one subject contest. If there is no database, it will be temporarily organized, which is not only a huge workload, it is also prone to errors and omissions. Therefore, it is necessary to arrange a dedicated person to be responsible for the maintenance of the database, and for the results obtained in the process of speciality construction and talent training, relevant certification materials and relevant information which should be scanned and entered into the database in a timely manner. Relevant data can be retrieved at any time when needed. Third, in accordance with the development trend of the foreign trade industry, cross-border ecommerce big data analysis, Python programming and other courses are added to the training plan; encourage teachers to carry out cross-border e-commerce big data and digital trade related research will be encouraged.

\section{CONCLUSION}

In order to meet the needs of society, applicationoriented universities should rely on mobile Internet and other digital technologies to build a value co-creation teaching ecosystem with employers. The construction of value co-creation teaching ecosystem can be guaranteed through these 8 ways and 4 systems. Relying on the mobile Internet, remote office, conferences and lectures can be carried out. Whether it is remote teaching, lectures, instructing competitions and internships for corporate personnel, temporary training for teachers in enterprises, or communication between schools and enterprises, they can all be carried out online. In addition, the development of digital technology makes professional digital transformation a trend. Whether it is teaching materials, teaching process or teaching supervision, digital transformation is needed.

\section{ACKNOWLEDGMENTS}

Fund Project: 2018 Shandong Provincial Colleges and Universities Undergraduate Teaching Reform Project "Research on the Construction of Applied Professionals (Group) Teaching Ecosystem under the Background of
Mobile Internet: Knowledge Sharing and Value Cocreation Dual Conceptual Perspective" (M2018X180), Shandong Provincial Colleges and Universities Undergraduate The teaching reform project "The Construction of a Multi-dimensional Ecosystem of Characteristic Classrooms in Colleges and Universities Based on the SPOC Teaching Model: Taking the Characteristics of Finance and Business Education of Shandong Institute of Business and Technology as an Example" (P2020022).

\section{REFERENCES}

[1] Zhang X.(2010) Construction and optimization of network teaching information ecosystem. China Educational Technology, 31: 26-29.

[2] Huang Z., Zhou R.(2020) Wan Liyong. Design and Empirical Research on Interactive Classroom Ecosystem in Blended Learning Environment. eEducation Research, 41:78-85.

[3] Zheng X., Yang X., Zhang J(2020). Research on the Evolution of Teacher-Student Teaching Relationship from the Perspective of Teaching EcoSystem: on the Evolution of Teacher-Student Teaching Relationship in the Era of Artificial Intelligence. China Educational Technology, 41 :39-45.

[4] Zhou Y.(2012) On the Teacher's Ecological Niche in the Ecosystem of Online Education. Technology Enhanced Foreign Language Education, 34: 20-25.

[5] Zheng Y.(2016) On the Construction of English Flipped Classroom Teaching Ecology. Foreign Language Research, 39: 124-127.

[6] Cao Y.(2016) Research on the ecology of flipped classroom teaching from the perspective of ecology. China Adult Education, 25:110-112.

[7] Xu Y., Tu Y.(2011) Research on Teaching Mode Based on Network Knowledge Ecosystem. China University Teaching, 33: 30-33.

[8] Lu B., Pan G., Zhang T., Hu B.(2016) Constructing the Ecosystems of Teaching Program in New Media Environment in High Education. Journal of China University of Petroleum(Edition of Social Sciences), 32: $98-102$. 